\title{
Development of an Educational Booklet for Women about Self Care During Pregnancy
}

Jilan A. Ibrahim Al-Battawi*,

Abstract: This study aimed at assessing the knowledge of women about pregnancy changes, self care during it, and development of an educational booklet based on the results of the assessment. The study was conducted at antenatal clinic at El-Shateby University Hospital. From the previous setting, a purposive sample consisting of 200 women was selected. A Structured Questionnaire sheet was developed and used to find out the knowledge and practice of the study sample about pregnancy changes and self care during it. The results found that the majority of women lack basic knowledge about pregnancy changes and self care during pregnancy.

\section{INTRODUCTION}

Currently, there is an international concern with women health. This because women are vulnerable group in the society and it has been shown that globally 500,000 women die each year because of reasons related to their reproductive function. Half of this death occurs in developing countries..$^{(1,2)}$

Globally every year more than 200 million women become pregnant. Mostof these pregnancies end with the birth of a live baby to a healthy mother, but for others, childbirth is not the joyous event it should be, but it is a time for pain, fear, suffering, and even death. Some of these pregnant women, $15 \%$, are likely to develop complications that need skilled obstetric care to prevent death or serious ill health.

In Egypt, the Maternal Mortality Rate (MMR) was reported to be 174 per 100,000 live births in $1992 / 1993,{ }^{(2,3)}$ the figure is considered very high when compared with figures recorded in the

*Gynecologic and Midwifery Nursing Department, Faculty of Nursing,

Alexandria University 
developed countries such as: 10 in The health of mothers and children is USA, ${ }^{4,5)} 7$ in the $U K,{ }^{(6)}$ and only 4 recognized to be closely related to the in Sweden in 1982. (7) general health of the community, as they

In recent years, the Egyptian constitute more than two-thirds of any Government conducted several community. The best method for investigations on maternal mortality. ensuring the health of expectant mother These researches revealed that $69.5 \%$ of and her infant is proper antenatal care. maternal deaths were due to direct Antenatal care has been downplayed in causes such as hemorrhage, eclampsia, recent years as an intervention for and genital tract infection, while $26.9 \%$ of reducing maternal morbidity and maternal deaths were due to indirect mortality. ${ }^{(11,12)}$

causes such as anemia, cardiovascular Moreover, during pregnancy and diseases, and infections. Many antenatal period, women experience underlying factors influence the capacity different types of pregnancy discomfort of women to survive complications which resulted from normal physiological emerging during pregnancy and changes that take place during childbirth. These factors include women's pregnancy. These discomforts if not health and nutritional status, access to anticipated by women and prepared to and use of health care services, as well face it, they can make women anxious, as knowledge, attitudes, and behavior of worried, and lead to adverse reaction by pregnant women. ${ }^{(8-10)}$ women which may hinder their health 
and development of risk complications such as anemia and infections. ${ }^{(13)}$

During pregnancy, women may have questions regarding healthy practices and lifestyle for their health and for the health of their babies such as healthy nutrition, rest, sleep, exercise, marital relation, and medications usage during pregnancy. ${ }^{(14)}$

One of the most important functions of antenatal care is to offer the woman advice and information about physiological changes during pregnancy, minor discomfort arises and how to cope with it, danger signs and symptoms and preparation for birth.

Antenatal care helps reduce the numbers and severity of pregnancyrelated complications by careful monitoring and early treatment of knowledge of women about pregnancy diseases aggravated during pregnancy, changes and self care during it, and to such as anemia. So it will contribute to develop an educational booklet to satisfy the maintenance and promotion of women's health during this critical period in their life. ${ }^{(15-17)}$

Antenatal period offers maternity nurses and midwives the opportunities for delivering health information and services that can significantly enhance the health of women and their infants. Maternity nurses and midwives are important resource persons within the reproductive health team, they are qualified to provide women with the necessary knowledge and information that help them to understand physiological changes during pregnancy, minor discomfort arises and how to cope with it, danger signs and symptoms and to prepare women for childbirth. So this study was carried out to assess the 
their needs. Also to provide maternity nurses and midwives with valid health education tools that enables them to provide quality and effective health education. Therefore, this study will be undertaken to develop an educational booklet for women and to help nurses and midwives to teach and counsel women about self care during pregnancy. ${ }^{(18-20)}$

\section{Aim of the study}

The aim of this study was to:-

- Assess the knowledge of women about pregnancy changes.

- Assess women's knowledge about self care during pregnancy, and

- Develop an educational booklet based on the results of the study.

\section{MATERIAL AND METHODS}

Material

Setting:
The study was undertaken in outpatient clinic at El-Shatbey Maternity University Hospital of Alexandria. The hospital provides antenatal care for normal pregnancy as well as for high risk antenatal patients who are usually referred from local primary health care centers.

\section{Subjects:}

A purposive sample consisting of 200 women attending the previous setting were randomly selected, and met the following criteria:

- In early pregnancy,

- Without any complication, and

- Just read and write

The researcher explained the purpose of the research to the study sample and obtained the sample approval to share in the research. The study was undertaken in outpatient clinic 
at El-Shatbey Maternity University Part three: Included questions to assess Hospital of Alexandria. the study samples' knowledge related to

\section{Tools:}

self care during pregnancy.

Two tools were developed and used for data collection.

A scoring system for women's knowledge regarding self care during Tool (1): A Structured Questionnaire sheet was developed and used for data collection concerning the knowledge of women's about pregnancy changes and their knowledge related to self care during it based on thorough review of current literature. It will be divided into three main parts:

10. The score was classified as 7.5

Part one: Included questions to identify points or more was considered good, 5the socio-demographic and biological less than 7.5 was considered fair, and characteristics of the sample such as age, education, occupation, gravidity, and parity. booklet based on the result of the Part two: Included questions to assess the study samples' knowledge related to pregnancy changes. less than 5 was considered poor.

Tool (2): Development of an educational Questionnaire sheet.

\section{Methods}

Permission to carry out this 
study was obtained from the responsible authorities of the selected settings. The researcher explained the purpose of the research to the study member, and obtained the sample approval to share in the research. A structured questionnaire sheet was developed. Data collection was conducted in antenatal clinic of the previously mentioned setting. Interviewing technique was used to assess the women's knowledge regarding self care during pregnancy.

\section{RESULTS}

Table (1) shows the sociodemographic and biological characteristics of the study sample. The table shows slightly that more than one half of the study sample (53\%) were between 25 to less than 30 years. While $29 \%$ were between 30 to less than 35 years.
The table also shows that more than two-thirds of the sample $(69 \%)$ just read \& write, while only $9 \%$ of the sample got secondary and /or more education.

As regards work experience, more than half of the study sample $(57.5 \%)$ were housewife, and one-fifth of them work without income. Only $22.5 \%$ were working with income. The table also shows that $42 \%$ were nulligravida and $58 \%$ were Multigravida. Also $47.5 \%$ were nullipara and $52.5 \%$ were multipara.

Table (2) represents the number and percent distribution of the study sample according to their knowledge about the importance of antenatal care. The table shows that about (80\%) gave wrong and didn't know the answer while, (12.50\%) gave correct and incomplete answer and only (7.50\%) gave correct and complete answer. 
Table (3) represents the number and percent distribution of the study sample according to their knowledge about changes during pregnancy. The table shows that $(57 \%)$ gave wrong and didn't know the answer while, (25\%) gave correct and incomplete answer, and only (18\%) gave correct and complete answer about breast changes during pregnancy. The table also shows that (59\%) gave wrong and didn't know the answer while, $(22.50 \%)$ gave correct and incomplete answer and only (18.50\%) gave correct and complete answer about the skin changes during pregnancy. As regard reproductive system changes during pregnancy the table illustrates that $(39 \%)$ gave wrong and didn't know the answer while, (50\%) gave correct and incomplete answer and only (11\%) gave correct and complete answer. Concerning the urinary system changes during pregnancy the table shows that (45\%) gave wrong and didn't know the answer while, (42.50\%) gave correct and incomplete answer and only (12.50\%) gave correct and complete answer. About (29.50\%) gave wrong and didn't know the answer while, (50.50\%) gave correct and incomplete answer and only (20\%) gave correct and complete answer regarding psychological changes during pregnancy. Moreover, (37\%) gave wrong and didn't know the answer while, (50\%) gave correct and incomplete answer and only (13\%) gave correct and complete answer about sexual desire changes during pregnancy.

Table (4) shows the number and percent distribution of the study sample according to their knowledge about hygiene of pregnancy. The table shows that $(60.50 \%)$ gave wrong and didn't 
know the answer while, (25\%) gave wrong and didn't know the answer while, correct and incomplete answer and only $(12.50 \%)$ gave correct and incomplete (14.50\%) gave correct and complete answer and only (7.50\%) gave correct answer regarding personal hygiene and complete answer. As regard comfort during pregnancy. In relation to suitable clothes during pregnancy $(61.50 \%)$ gave wrong and didn't know the answer while, (25\%) gave correct and incomplete and only (13.50\%) gave correct and complete answer. Concerning comfort shoes during pregnancy (78.50\%) gave wrong answer while, (5\%) gave correct and and didn't know the answer while, (15\%) incomplete answer and only (2\%) gave gave correct and incomplete answer and only $(6.50 \%)$ gave correct and complete answer. Regarding exercises allowed during pregnancy $(90.50 \%)$ gave wrong and didn't know the answer while, (5\%) gave correct and incomplete answer and only $(4.50 \%)$ gave correct and complete answer. In relation to sleeping duration during the day and night $(80 \%)$ gave correct and completer answer about sexual relation allowed and not allowed during pregnancy. Regarding sexual position in the pregnancy (72\%) gave wrong and didn't know the answer while, (18\%) gave correct and incomplete answer and only (10\%) gave correct and complete answer. Also the table shows that $(79 \%)$ gave wrong and didn't know 
the answer while, (13.50\%) gave correct and incomplete and only $(7.50 \%)$ gave correct and complete answer about traveling. Regarding medications $(91.50 \%)$ gave wrong and didn't know the answer while (5\%) gave correct and incomplete answer and only (3.50\%) gave correct and complete answer. As regard radiation $90 \%$ gave wrong and didn't know the answer while, $6 \%$ gave correct and incomplete answer and only $4 \%$ gave correct and complete answer. Moreover, $88.50 \%$ gave wrong and didn't know the answer while, 7\% gave correct and incomplete answer and only $4.5 \%$ gave correct and complete answer about smoking and passive smokers.

Table (5) shows the number and percent distribution of the study sample according to their knowledge about nutrition during pregnancy, it shows that
$93 \%$ gave wrong and didn't know the answer while, 4\% gave correct and incomplete and only $3 \%$ gave correct and complete answer about elements of balanced diet. Regarding food rich in iron $83.50 \%$ gave wrong and didn't know the answer while, (10\%) gave correct and incomplete answer and only (7\%) gave correct and complete answer. Concerning importance and amount of fluid per day (42\%) gave wrong and didn't know the answer while, (45\%) gave correct and incomplete answer and only (13\%) gave correct and complete answer. As regard division of main meals and snacks (88\%) gave wrong and didn't know the answer while, (7\%) gave correct and incomplete answer and only (5\%) gave correct and complete answer. Table (6) represents the number and percent distribution of the study sample 
according to their knowledge about minor discomforts of pregnancy and how to relieve it. The table shows that $89.50 \%$ gave wrong and didn't know the answer while, $6.50 \%$ gave correct and incomplete answer and only $4 . \%$ gave correct and complete answer about gums and teeth. Regarding morning sickness and vomiting $91 \%$ gave wrong and didn't know the answer while, $6 \%$ gave correct and incomplete answer and only 3\% gave correct and complete answer. As regard heart burn $87.50 \%$ gave wrong and didn't know the answer while, $7.50 \%$ gave correct and incomplete answer and only $5 \%$ gave correct and complete answer. Concerning constipation 58\% gave wrong and didn't know the answer while, $30 \%$ gave correct and incomplete answer and only $12 \%$ gave correct and complete answer. Regarding hemorrhoids $76 \%$ gave wrong and didn't know the answer while, 15\% gave correct and incomplete answer and only 9\% gave correct and complete answer. In relation to varicose vein $69 \%$ gave wrong and didn't know the answer while, $20 \%$ gave correct and incomplete and only $11 \%$ gave correct and complete answer. As regard limb edema $72 \%$ gave wrong and didn't know the answer while, $20 \%$ gave correct and incomplete answer and only $8 \%$ gave correct and complete answer. Concerning leg cramps 93\% gave wrong and didn't know the answer while $5 \%$ gave correct and incomplete answer and only $2 \%$ gave correct and complete answer. The table also shows that $66 \%$ gave wrong and didn't know the answer while, $25 \%$ gave correct and incomplete answer and only $9 \%$ gave correct and complete answer about 
urinary frequency. Moreover $73.50 \%$ gave wrong and didn't know the answer while, $20 \%$ gave correct and incomplete answer and only $6.50 \%$ gave correct and complete answer. about vagind dischavge.

Table (7) represents the number and percent distribution of the study sample according to their knowledge about warning signs during pregnancy and how to relieve it. The table shows that $69.50 \%$ gave wrong and didn't know the answer while, $25 \%$ gave correct and incomplete answer and only $5.50 \%$ gave correct and complete answer about absence of fetal movement. Regarding sudden increase in abdominal size $94 \%$ gave wrong and didn't know the answer while, $4 \%$ gave correct and incomplete answer and only $2 \%$ gave correct and complete answer.
Concerning excessive weight gain in short period $91 \%$ gave wrong and didn't know the answer while,5\% gave correct and incomplete answer and only 4\% gave correct and complete answer. As regard severe persistent headache $79 \%$ gave wrong and didn't know the answer while, $12 \%$ gave correct and incomplete answer and only 9\% gave correct and complete answer. In relation to blurring of vision $83.50 \%$ gave wrong and didn't know the answer while, $10 \%$ gave correct ands incomplete answer and only $6.50 \%$ gave correct and complete answer. Regarding generalized edema $87 \%$ gave wrong and didn't know the answer while, $10 \%$ gave correct and incomplete answer and only $3 \%$ gave correct and complete answer.

Concerning bleeding even spots $84 \%$ gave wrong and didn't know the answer 
while, $10 \%$ gave correct and incomplete answer and only 6\% gave correct and complete answer. Moreover, 79\% gave wrong and didn't know the answer while, $15 \%$ gave correct and incomplete answer and only $6.00 \%$ gave correct and complete answer about leakage of liquor.

Table (8) represents the number and percent distribution of the study sample according to their knowledge about true signs of labor and what to do during this period. The table shows that $67.50 \%$ gave wrong and didn't know the answer while, $20 \%$ gave correct and incomplete answer and only $12.50 \%$ gave correct and complete answer about signs of labor. On the other hand, $70.50 \%$ gave wrong and didn't know the answer while, $15 \%$ gave correct and incomplete answer and only $14.5 \%$ gave correct and complete answer with respect to clothes of mother and baby. Correct.
Table (9) shows the number and percent distribution of the study sample according to their sources of information about pregnancy changes and self care during it. The table represents $49 \%$ and $53 \%$ get their information from either last pregnancy experience or from their biological mothers or mothers in law. Also from radio and TV were reported by $42.5 \%$ and nurses as a source of their information were reported by $41 \%$ followed by friends $29.5 \%$ and then physician reported by $27 \%$ of the study sample.

\section{DISCUSSION}

Pregnancy is a physiological process that is accompanied by various changes in all body systems. These changes produce some minor discomforts such as morning sickness, heart burn, constipation, hormonal and emotional 
changes related to the growing uterus, related to antenatal care and pregnancy. and postural changes as the body About more than one half and oneaccommodates to pregnancy. These quarter of the study sample had wrong minor discomforts can be troublesome, answer or didn't know the answer but most of them are self-limiting and related to importance of antenatal care disappear during pregnancy or after the (table 2). Three-fifths of the study sample birth of the baby. ${ }^{(21,22)}$

knew the reproductive system changes

It is important for every pregnant during pregnancy, while more than half woman to have knowledge about of the study sample had wrong answer or physiological and psychological didn't know the answer about breast changes during pregnancy, and to changes during pregnancy. As regard practice its hygiene properly. So knowledge about psychological changes antenatal period offers opportunities for during pregnancy, near to threedelivering health information and quarters had correct answer and less services that can significantly enhance than two-thirds gave correct answer the health of women and their infants. related to sexual desire changes during The present study revealed that nearly pregnancy (table 3). three-quarters of the study sample just In relation to hygiene during read and write (table 1). Most of the pregnancy, about two-fifths of the study study sample had wrong or don't know sample had correct answer. Also the the correct answer of the question study revealed that only near to one- 
tenth of the study sample knew exercises allowed during pregnancy (table 4). These findings are in line with that of Jean (2002) who found- in a study done in USA about exercises during pregnancy- that two-thirds of his study sample did perform the recommended daily exercises during pregnancy. ${ }^{(23)}$ One-fifth of the study sample had correct answer about sleeping duration during day and night (table 4). These findings are in line with the findings od the National Sleep Foundation (NFS) in London (1998) where they did a study about pattern of sleep during pregnancy. They reported that about three-fourths of their study sample had disturbed sleeping patterns. ${ }^{(24)}$

In relation to nutrition during the vast majority of the study sample had wrong answer or don't know the answer related to elements of balanced diet, food rich in iron, and division of main meals and snacks (table 5). This result is in line with the findings of Rashad (2001) who had conducted a study about dietary habit of pregnant women in Alexandria. She reported that her sample lacked both the knowledge as well as the proper practices in choosing their meal components. ${ }^{(25)}$

In relation to minor discomforts occurring during pregnancy and how to relive them, the majority of study sample had wrong answer or didn't know as regard morning sickness and vomiting (table 6). This result is in line with the result of Waddell (1995) who stated that occurrence of nausea and vomiting during pregnancy is a common complain $^{(26)}$. Also the majority of the study sample used harmful practices to 
relief nausea and vomiting. This result is in line with Scott et al who mentioned that excessive intake of sodium should be discourage during pregnancy because it may contribute to abnormal fluid retention and edema. ${ }^{(27)}$ This result is in congruence with Wills (2005) who found out that more than one half of his study sample did try to avoid fatty, spicy, and fried foods and ate a small frequent meals (snacking) along the day to relive nausea. ${ }^{(28)}$ As regard heart burn, the majority of the study sample had answer or don't know. This result was in line with Melokhia (1986) who found that $84 \%$ of her study subjects had not any knowledge about heart burn and also did harm to treat it. ${ }^{(29)}$ Also the result of the present study is in congruence with Platkin's (2005) who found that most of his study sample did't eat spicy, fried or fatty foods. Spicy and acidic foods can further irritate an esophagus that has been damaged by acid reflux and increase the sensation of heartburn. ${ }^{(30)}$ In relation to constipation more than twofifths of the study sample had correct answer (table 6), while nearly three-fifths performed harmful practices to relief this discomfort or didn't know how to relief it. This in contrast with Owen who stated that the majority of his sample drank cold milk at bed time, this health practice is healthy and acceptable. ${ }^{(31)}$ Regarding minor discomfort occurring in circulatory system less than one-quarter of the study sample gave correct answer about headache, one-third gave correct answer about varicose vein, more than onequarter gave correct answer related to lower limb edema, and less than onetenth gave correct answer about leg 
cramp. This result is in line with Heiba (2001) who denoted that a majority of women having knowledge about minor discomforts occurring in circulatory system $\left.^{(32}\right)$. In addition, two-thirds of the study sample responded wrongly and didn't know the answer in regarding urinary frequency as a minor discomfort of genitourinary system. On the other hand, less than three-quarters gave wrong answer or didn't know the answer related to vaginal discharge (table 6). This result is in congruence with Guise (2001) who found three-fourths of his study sample were making perineal care to decrease vaginal discharge beside other measures such as local application for crème or antibiotics. ${ }^{(33)}$

As regard knowledge about warning signs during pregnancy, less than onethird of the study sample knew absence of fetal movement, less than one-tenth knew increase of the abdominal size as a warning sign during pregnancy, also a less than one-tenth had correct answer about excessive weight gain in short duration, one-fifth had correct answer about severe persistent headache, while less than one-fifth gave correct answer about blurring of vision. Moreover, generalized edema only more than onetenth responded correctly. On the other hand, less than one-fifth had correct answer about bleeding as a warning sign during pregnancy (table 7). This result is in line with El-Zanaty and Way who stated that the women with age 45-49 and with no education were least likely to have heard messages about warning signs of pregnancy. (34)

Concerning the knowledge about signs of labor, less than one-third knew 
the correct answer, also near to three-quarters gave wrong or didn't know the answer about mother and infant clothes (table 8). In relation to the sources of knowledge, the majority of the study sample get their information from last pregnancy experience or from biological mothers or mothers in law. Radio and TV were reported by more than two-fifths. Also nurses were reported by two-fifths followed by friends were reported by less than one-third, while only the physicians were reported by more than one-quarter.

\section{CONCIUSION}

Assessing knowledge related to different reproductive health issues generally revealed inadequacy of women's knowledge especially in developing countries. According to result of the present study, it can be concluded that there is lack of knowledge regarding importance of antenatal care, physiological and psychological changes during pregnancy, hygiene of pregnancy, nutrition during pregnancy, minor discomfort and warning signs, true signs of labor, and preparation for labor. This may be due to nearly to three-quarters of the study sample just read and write and also nearly to three-fifths of the study sample were housewife, and one-fifth work without income. So there is an important need for an educational booklet about self care during pregnancy.

\section{RECOMMENDATIONS}

Based on the results of the current research, the following recommendations are proposed:

1- The assessment of pregnant women's status as well as needspecially history taking-must include 
some questions about their self care practices.

2- Pregnant women should have an accurate information about physiological and psychological changes during pregnancy, hygiene of pregnancy, minor discomforts warning signs, and preparation for labor.

3- Antenatal health education should considere the reinforcement or modification of pregnant women's self care practices according to their benefit versus harm.

4- Adequate and variable books and magazine should be available in all services which offer antenatal care.

5- Proper and qualified care should be provided to all aspects, pregnant women including educational counseling. 
Table (1): Number and percent distribution of the study sample according to their socio-demographic and biological characteristics.

\begin{tabular}{|c|c|c|}
\hline Personal characteristics & No. $=200$ & $\%$ \\
\hline $\begin{array}{l}\text { Age in years } \\
20- \\
25- \\
30- \\
35+\end{array}$ & $\begin{array}{c}22 \\
106 \\
58 \\
14\end{array}$ & $\begin{array}{c}11.00 \\
53.00 \\
29.00 \\
7.00\end{array}$ \\
\hline Mean \pm SD & \multicolumn{2}{|c|}{$29.1 \pm 3.81$} \\
\hline $\begin{array}{l}\text { Educational background } \\
\text { Read \& write } \\
<\text { Secondary } \\
\text { Secondary + }\end{array}$ & $\begin{array}{c}138 \\
44 \\
18\end{array}$ & $\begin{array}{c}69.00 \\
22.00 \\
9.00\end{array}$ \\
\hline $\begin{array}{l}\text { Work experiences } \\
\text { Housewife } \\
\text { Work with income } \\
\text { Work without income }\end{array}$ & $\begin{array}{c}115 \\
45 \\
40\end{array}$ & $\begin{array}{l}57.50 \\
22.50 \\
20.00\end{array}$ \\
\hline $\begin{array}{l}\text { Gravidity } \\
\text { Primigravida } \\
\text { Multigravida }\end{array}$ & $\begin{array}{c}84 \\
116\end{array}$ & $\begin{array}{l}42.00 \\
58.00\end{array}$ \\
\hline $\begin{array}{l}\text { Parity } \\
\text { Nullipara } \\
\text { Multipara }\end{array}$ & $\begin{array}{c}95 \\
105\end{array}$ & $\begin{array}{l}47.50 \\
52.50\end{array}$ \\
\hline
\end{tabular}

Table (2) Number and percent distribution of the study sample according to their knowledge about the importance of antenatal care.

\begin{tabular}{|l|c|c|}
\hline Responses & No. = 200 & $\%$ \\
\hline Correct and complete & 15 & 7.50 \\
Correct and incomplete & 25 & 12.50 \\
Wrong and didn't knew & 160 & 80.00 \\
\hline
\end{tabular}


Table 3 : Number and percent distributions of the study sample according to their knowledge about changes during pregnancy

\begin{tabular}{|c|c|c|}
\hline Responses & No. $=200$ & $\%$ \\
\hline $\begin{array}{l}\text { Physiological changes: } \\
\text { Breast changes } \\
\text { Correct and complete } \\
\text { Correct and incomplete } \\
\text { Wrong and didn't knew }\end{array}$ & $\begin{array}{c}36 \\
50 \\
114\end{array}$ & $\begin{array}{l}18.00 \\
25.00 \\
57.00\end{array}$ \\
\hline $\begin{array}{l}\text { Skin changes } \\
\text { Correct and complete } \\
\text { Correct and incomplete } \\
\text { Wrong and didn't knew }\end{array}$ & $\begin{array}{c}37 \\
45 \\
118\end{array}$ & $\begin{array}{l}18.50 \\
22.50 \\
59.00\end{array}$ \\
\hline $\begin{array}{l}\text { Reproductive system changes } \\
\text { Correct and complete } \\
\text { Correct and incomplete } \\
\text { Wrong and didn't knew }\end{array}$ & $\begin{array}{c}22 \\
100 \\
78\end{array}$ & $\begin{array}{l}11.00 \\
50.00 \\
39.00\end{array}$ \\
\hline $\begin{array}{l}\text { Urinary system changes } \\
\text { Correct and complete } \\
\text { Correct and incomplete } \\
\text { Wrong and didn't knew }\end{array}$ & $\begin{array}{l}25 \\
85 \\
90\end{array}$ & $\begin{array}{r}12.50 \\
42.50 \\
45.00\end{array}$ \\
\hline $\begin{array}{l}\text { Psychological changes: } \\
\text { Correct and complete } \\
\text { Correct and incomplete } \\
\text { Wrong and didn't knew }\end{array}$ & $\begin{array}{c}40 \\
101 \\
59\end{array}$ & $\begin{array}{l}20.00 \\
50.50 \\
29.50\end{array}$ \\
\hline $\begin{array}{l}\text { Changing in sexual desire } \\
\text { Correct and complete } \\
\text { Correct and incomplete } \\
\text { Wrong and didn't knew }\end{array}$ & $\begin{array}{c}26 \\
100 \\
74\end{array}$ & $\begin{array}{l}13.00 \\
50.00 \\
37.00\end{array}$ \\
\hline
\end{tabular}


Table 4 : Number and percent distributions of the study sample according to their knowledge about hygiene of pregnancy

\begin{tabular}{|c|c|c|}
\hline Responses & No. $=\mathbf{2 0 0}$ & $\%$ \\
\hline Personal hygiene & & \\
\hline Correct and complete & 29 & 14.50 \\
\hline Correct and incomplete & 50 & 25.00 \\
\hline Wrong and didn't knew & 121 & 60.50 \\
\hline Suitable clothes during pregnancy & & \\
\hline Correct and complete & 27 & 13.50 \\
\hline Correct and incomplete & 50 & 25.00 \\
\hline Wrong and didn't knew & 123 & 61.50 \\
\hline Characteristics of comfort shoes & & \\
\hline Correct and complete & 13 & 6.50 \\
\hline Correct and incomplete & 30 & 15.00 \\
\hline Wrong and didn't knew & 157 & 78.50 \\
\hline Exercises allowed during pregnancy & & \\
\hline Correct and complete & 9 & 4.50 \\
\hline Correct and incomplete & 10 & 5.00 \\
\hline Wrong and didn't knew & 181 & 90.50 \\
\hline Sleep duration during day and night & & \\
\hline Correct and complete & 15 & 7.50 \\
\hline Correct and incomplete & 25 & 12.50 \\
\hline Wrong and didn't knew & 160 & 80.00 \\
\hline Comfort sleeping positions in late pregnancy & & \\
\hline Correct and complete & 6 & 3.00 \\
\hline Correct and incomplete & 8 & 4.00 \\
\hline Wrong and didn't knew & 186 & 93.00 \\
\hline $\begin{array}{l}\text { Sexual relation, when allowed \& when should } \\
\text { be not allowed }\end{array}$ & 4 & 2.00 \\
\hline Correct and complete & 10 & 5.00 \\
\hline Correct and incomplete & 186 & 93.00 \\
\hline Wrong and didn't knew & & \\
\hline Sexual positions in late pregnancy. & & \\
\hline Correct and complete & 20 & 10.00 \\
\hline Correct and incomplete & 36 & 18.00 \\
\hline Wrong and didn't knew & 144 & 72.00 \\
\hline Traveling & & \\
\hline Correct and complete & 15 & 7.50 \\
\hline Correct and incomplete & 27 & 13.50 \\
\hline Wrong and didn't knew & 158 & 79.00 \\
\hline Medications & & \\
\hline Correct and complete & 7 & 3.50 \\
\hline Correct and incomplete & 10 & 5.00 \\
\hline Wrong and didn't knew & 183 & 91.50 \\
\hline Radiations & & \\
\hline Correct and complete & 8 & 4.00 \\
\hline Correct and incomplete & 12 & 6.00 \\
\hline Wrong and didn't knew & 180 & 90.00 \\
\hline Smoking and passive smokers & & \\
\hline Correct and complete & 9 & 4.50 \\
\hline Correct and incomplete & 14 & 7.00 \\
\hline Wrong and didn't knew & 177 & 88.50 \\
\hline
\end{tabular}


Table 5: Number and percent distribution of the study sample according to their knowledge about nutrition during pregnancy.

\begin{tabular}{|l|c|c|}
\hline Responses & No. = 200 & $\%$ \\
\hline Elements of balanced diet & 6 & \\
Correct and complete & 8 & 3.00 \\
Correct and incomplete & 186 & 93.00 \\
Wrong and didn't knew & & \\
\hline Food rich in iron & 14 & 7.00 \\
Correct and complete & 20 & 10.00 \\
Correct and incomplete & 166 & 83.00 \\
Wrong and didn't knew & & \\
Importance and amount of fluid per day & 26 & 13.00 \\
Correct and complete & 90 & 45.00 \\
Correct and incomplete & 84 & 42.00 \\
Wrong and didn't knew & & \\
\hline Division of main meals and snacks & 10 & 5.00 \\
Correct and complete & 14 & 7.00 \\
Correct and incomplete & 176 & 88.00 \\
Wrong and didn't knew & & \\
\hline
\end{tabular}

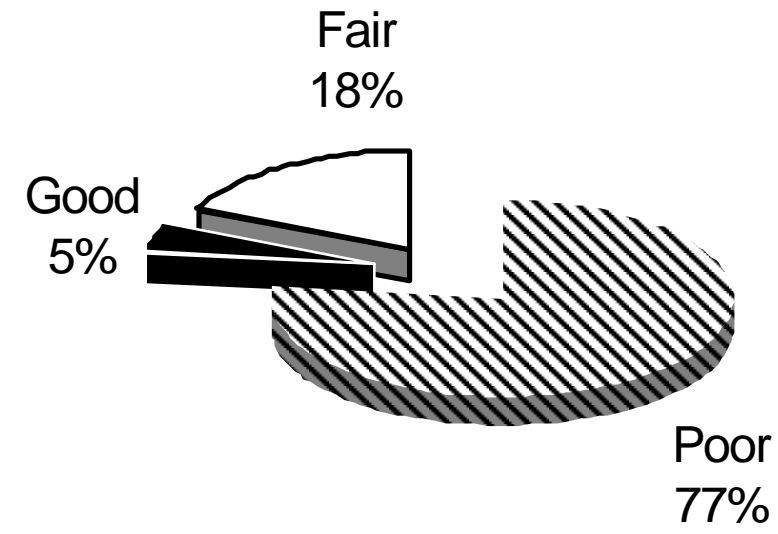

Figure (1): Distribution of the study subjects according to total score of knowledge 
Table 6 : Number and percent distribution of the study sample according to their knowledge about minor discomforts occurring during pregnancy and how to relieve it.

\begin{tabular}{|c|c|c|}
\hline Responses & No. $=200$ & $\%$ \\
\hline $\begin{array}{l}\text { Gastrointestinal system: } \\
\text { Gums and teeth } \\
\text { Correct and complete } \\
\text { Correct and incomplete } \\
\text { Wrong and didn't knew }\end{array}$ & $\begin{array}{c}8 \\
13 \\
179\end{array}$ & $\begin{array}{c}4.00 \\
6.50 \\
89.50\end{array}$ \\
\hline $\begin{array}{l}\text { Morning sickness and vomiting } \\
\text { Correct and complete } \\
\text { Correct and incomplete } \\
\text { Wrong and didn't knew }\end{array}$ & $\begin{array}{c}6 \\
12 \\
182\end{array}$ & $\begin{array}{c}3.00 \\
6.00 \\
91.00\end{array}$ \\
\hline $\begin{array}{l}\text { Heartburn } \\
\text { Correct and complete } \\
\text { Correct and incomplete } \\
\text { Wrong and didn't knew }\end{array}$ & $\begin{array}{c}10 \\
15 \\
175\end{array}$ & $\begin{array}{c}5.00 \\
7.50 \\
87.50\end{array}$ \\
\hline $\begin{array}{l}\text { Constipation } \\
\text { Correct and complete } \\
\text { Correct and incomplete } \\
\text { Wrong and didn't knew }\end{array}$ & $\begin{array}{c}24 \\
60 \\
116 \\
\end{array}$ & $\begin{array}{l}12.00 \\
30.00 \\
58.00\end{array}$ \\
\hline $\begin{array}{l}\text { Circulatory system: } \\
\text { Hemorrhoids } \\
\text { Correct and complete } \\
\text { Correct and incomplete } \\
\end{array}$ & $\begin{array}{c}18 \\
30 \\
152\end{array}$ & $\begin{array}{c}9.00 \\
15.00 \\
76.00\end{array}$ \\
\hline $\begin{array}{l}\text { Varicose vein } \\
\text { Correct and complete } \\
\text { Correct and incomplete } \\
\quad \text { Wrong and didn't knew }\end{array}$ & $\begin{array}{c}22 \\
40 \\
138\end{array}$ & $\begin{array}{l}11.00 \\
20.00 \\
69.00\end{array}$ \\
\hline $\begin{array}{l}\text { Lower limb edema } \\
\text { Correct and complete } \\
\text { Correct and incomplete }\end{array}$ & $\begin{array}{c}16 \\
40 \\
144\end{array}$ & $\begin{array}{c}8.00 \\
20.00 \\
72.00\end{array}$ \\
\hline $\begin{array}{l}\text { Leg cramps } \\
\text { Correct and complete } \\
\text { Correct and incomplete } \\
\text { Wrong and didn't knew }\end{array}$ & $\begin{array}{c}4 \\
10 \\
186\end{array}$ & $\begin{array}{c}2.00 \\
5.00 \\
93.00\end{array}$ \\
\hline $\begin{array}{l}\text { Genitourinary system: } \\
\text { Urinary frequency } \\
\text { Correct and complete } \\
\text { Correct and incomplete } \\
\text { Wrong and didn't knew }\end{array}$ & $\begin{array}{c}18 \\
50 \\
132\end{array}$ & $\begin{array}{c}9.00 \\
25.00 \\
66.00\end{array}$ \\
\hline $\begin{array}{l}\text { Vaginal discharge } \\
\text { Correct and complete } \\
\text { Correct and incomplete } \\
\text { Wrong and didn't knew }\end{array}$ & $\begin{array}{c}13 \\
40 \\
147\end{array}$ & $\begin{array}{c}6.50 \\
20.00 \\
73.50\end{array}$ \\
\hline
\end{tabular}


Table 7: Number and percent distribution of the study sample according to their knowledge about warning signs during pregnancy and how to relieve it.

\begin{tabular}{|l|c|c|}
\hline Warning signs during pregnancy & $\begin{array}{c}\text { No. } \\
\mathbf{2 0 0}\end{array}$ & $\%$ \\
\hline Absence of fetal movement & 11 & 5.50 \\
Correct and complete & 50 & 25.00 \\
Correct and incomplete & 139 & 69.50 \\
Wrong and didn't knew & & \\
\hline Sudden increase in the abdominal & 4 & 2.00 \\
size & 8 & 4.00 \\
Correct and complete & 188 & 94.00 \\
Correct and incomplete & & \\
Wrong and didn't knew & & \\
\hline Excessive weight gain in short period & 8 & 4.00 \\
Correct and complete & 10 & 5.00 \\
Correct and incomplete & 182 & 91.00 \\
Wrong and didn't knew & & \\
\hline Severe persistent headache & 18 & 9.00 \\
Correct and complete & 24 & 12.00 \\
Correct and incomplete & 158 & 79.00 \\
Wrong and didn't knew & & \\
\hline Blurring of vision & 13 & 6.50 \\
Correct and complete & 20 & 10.00 \\
Correct and incomplete & 167 & 83.5 \\
Wrong and didn't knew & & \\
\hline Generalized edema & 6 & 3.00 \\
Correct and complete & 20 & 10.00 \\
Correct and incomplete & 174 & 87.00 \\
Wrong and didn't knew & 12 & 6.00 \\
\hline Bleeding even spots & 168 & 84.00 \\
Correct and complete & 158 & 79.00 \\
Correct and incomplete & & \\
Wrong and didn't knew & & \\
\hline Leakage of liquor & & \\
Correct and complete & & \\
Correct and incomplete & & \\
Wrong and didn't knew & & \\
\hline & & \\
\hline
\end{tabular}


Table 8 :Number and percent distribution of the study sample according to their knowledge about labor and what to do during this period.

\begin{tabular}{|l|c|c|}
\hline knowledge about labor & No. = 200 & $\%$ \\
\hline Signs of labor & 25 & 12.50 \\
Correct and complete & 40 & 20.00 \\
Correct and incomplete & 135 & 67.50 \\
Wrong and didn't knew & & \\
\hline Clothes for mother and baby & 29 & 14.50 \\
Correct and complete & 30 & 15.00 \\
Correct and incomplete & 141 & 70.50 \\
Wrong and didn't knew & & \\
\hline
\end{tabular}

Table 9 :Number and percent distribution of the study sample according to their Sources of information about pregnancy changes and self care during it.

\begin{tabular}{|c|c|c|}
\hline Sources of their information & No. $=200$ & $\%$ \\
\hline - $\quad$ Last experience & 98 & 49.00 \\
\hline - $\quad$ Mother \& or mother in law & 106 & 53.00 \\
\hline - Friends & 59 & 29.50 \\
\hline - Radio \& TV & 85 & 42.50 \\
\hline - Physician & 54 & 27.00 \\
\hline - Nurses & 82 & 41.00 \\
\hline
\end{tabular}

The respondents gave more than one answer. 


\section{REFERENCES}

1. Development and research training in human reproductive. Antenatal services and delivery care 1997; NO. 42, part 1. Available from: URL: http// www.pubmedecentral.nih.gov. I ast accessed on: February 2007.

2. WHO. Mother-baby package: Implementing Safe Motherhood in countries. Geneva. WHO; 1994.1-7

3. Ministry of Health. Survival projects; USAID. National Maternal Mortality Study Egypt: MOH;2000-2001.

4. Rochaz RW. Maternal mortality in the United States of America.

World Health Statistics Quarerly. 1981; 34:2-13.

5. Kaunitz AM, Hughes JM, Grimes DA - Causes of maternal mortality in United States. Obstet \& Gyne. 1985; 65:605.

6. MacFarlane A, Ford M. Birth counts: statistics of pregnancy and childbirth. London: Her Majesty's Stationary Office, 1984; 71-5

7. Hogberg U. Maternal mortality in Sweden. Umea, Sweden: Umea University; 1985.

8. Ministry of Health. National Maternal Mortality Study Egypt:MOHP; 19921993.

9. Goodrum LA. Maternal Mortality: Strategies in prevention and care. Hospital Physician. January 2001; 44-51.

10. Donnary F, Csete J. Programming for Safe Motherhood: guidelines for maternal and neonatal survival. $1^{\text {st }}$ ed. UNICEF Headquarters;1999. 130.
11. World Health Organization. Roystone and Armstrong: preventing maternal deaths. Geneva: World Health Organization;1989

12. Gree L, Ottoson J. Community and population health. $8^{\text {th }}$ ed. Mexico City: McGraw Hill Companies; 1999. 125-126.

13. Burroughs A, Leifer G. Maternity Nursing: An Introductory text. $8^{\text {th }}$ ed. W.B.Saunders Co, 2001.49-57.

14. http://www.emro.who.int/ making preganancy safer, Damascus, Syrian Arab Republic, 9-11 April 2007.

15. Lumbiganon P. Appropriate technology: antenatal care. Int $\mathrm{J}$ Gynaecol Obstet. 1998;

16. Pittrof $R$, Campbell OM, Filippi VG. What is quality in maternity care? An Int Gynecol Scand. 2002; 81: 277-83.

17. World Health Organization, Department of Reproductive Health and Research, Family integrated management of pregnancy and childbirth. Pregnancy, childbirth, postpartum for essential practice. Geneva: Switzerland. WHO; 2003.

18. Margaret D, Ralph C, Irene $M$. Maternity Care: the nurse and the family. $1^{\text {st }}$ ed. Saint Louis: Mosby Co; 2002.

19. Carroli G, Rooney C, Villar J, WHO Programme to Map the Best Reproductive Health Practices. How effective is antenatal care in preventing mortality and serious morbidity? Paediatric and Perinatal Epidemiology. 2001;15, suppl 1.

20. WHO antenatal care randomized trial. 
Manual for the implementation of the new model. WHO/RHR/01.30.Geneva, World Health Organization; 2001.

21. Adams M. Bailliere's midwives' dictionary. $7^{\text {th }}$ ed. London. ELBS Com, 1999;36:74:198.

22. El-Sherbeni F. A study of knowledge and practice of women related to self care during pregnancy in Kuwait. Doctorate Thesis submitted to High Institute of Public Health, Alexandria University;1998.

23. Jean P. Pay attention to special exercise needs when pregnant, experts say.2002. Available from: http://proqusese.umi.com.ezproxy.m atc

24. Wood G. Tetanus in pregnancy. American Journal of Perinatology. 2003; 4: 173-82.

25. Rashad W. study for Developing and testing A Nutritional Educational Booklet for low-literate Pregnant women. D.S. Thesis. University of Alexandria Faculty of Nursing, 2001; 6:61-76.

26. Waddell A. Women's health, improve our health, improve the world, Geneva: Who; 1995.6-8.

27. Scott L, Kozinetz C, Gonik B. Gastrointestinal function in pregnancy. 1996;90:1624.
28. Wills G. Nausea and vomiting in pregnancy what advices do midwives give? 2005. Available from: science direct-midwifery: nausea and vomiting in pregnancy $\mathrm{htm}$.

29. Molokhia S. A descriptive study of knowledge and practices of pregnant women in the relief of selected minor discomforts during the last trimester of pregnancy. Master Thesis submitted to High Institute of Nursing, Alexandria University, 1986.

30. Platkin C. A guide to heartburn. 2005. Available from: http://proquest.umi.com.ezproxy.edu/ pQdweb.

31. Owen P. Constipation during pregnancy. 2005. Avaliable from: http://proquest.umi.com.ezproxy.edu/ pQdweb.

32. Hieba M. Home remedies used to relief pregnancy-related complaints among expected mothers in AlSalam district in Port Said. Master Thesis submitted to Faculty of Nursing, Suez Canal University, 2001.

33. Guise M. Screening for bacterial vaginal infection in pregnancy. Journal of American and aural of preventive Medicine. 2001;20:62-72.

34. El-Zanaty F, Way AA. Egypt demographic and health survey. November 2003. Cairo: National Population Council; 2000;13. 